Man M. S.

Idealogy Journal of Arts and Social Science, 2018

Vol. 3, No. 2, 255-264

\title{
Integration of UiTM Perak Campus with Tourism Malaysia Perak as an Academic Community
}

\section{Integrasi Kampus UiTM Perak Bersama Tourism Malaysia Perak Sebagai Komuniti Akademik}

\author{
Mohamad Sohaimi Man \\ Jabatan Seni Bina, Universiti Teknologi MARA Perak Branch, Seri Iskandar Campus, \\ 32610 Seri Iskandar, Perak, MALAYSIA \\ Author email: sohaimi810@uitm.edu.my \\ Published: 7 September 2018
}

\begin{abstract}
Tourism is a unique product and a mixture of tangible and intangible elements and an inspiration in daily life activities. It is recognized as an economic catalyst and the generation of local, state and country through the diversity of attractions such as the impact of heritage, natural beauty of Allah SWT creation until the culture and behaviour of the local community. This is an existing asset as commercialist products in the promotion of tourism industry in the country. Following that, a tourist attraction for coming to our country can be processed and innovated through the integration of three components namely as universities, travel agencies and local communities. Such integration can create partnerships towards centering elements of local history from various aspects such as visual arts, cultural and environmental patterns. University became the main role is to be realized as the first tourist destination before heading to any other destination. Rationally, Universiti Teknologi MARA Cawangan Perak can serve as a transit centre for academic information academic commercialization patterned tour through cooperation with travel agencies and local communities. This is an academic innovation that can be implemented through a mechanism that is to bring the university to the community and not community to the university. This is an added value in enhancing the delivery of information to be shared with the public interest, in line with the university's objective to improve relations and cooperation with international organizations in the activities of the network in the industry to help the country through the promotion of the tourism industry. These efforts will be successful if there is extensive involvement of the university community and travel agencies, local communities, state governments and government agencies or the private sector is prepared to give a commitment and cooperation at its best communities.
\end{abstract}

Keywords: integration, university, transit travellers

\begin{abstract}
ABSTRAK
Pelancongan adalah satu produk yang unik dan merupakan satu campuran unsur ketara dan tidak ketara dan merupakan inspirasi dalam aktiviti kehidupan harian. Ia diiktiraf sebagai pemangkin dan penjanaan ekonomi sesebuah tempat, negeri dan negara melalui kepelbagaian tarikan seperti kesan peninggalan sejarah, keindahan alam ciptaan Allah SWT sehinggalah kepada kebudayaan dan perilaku masyarakat setempat. Ini merupakan satu aset 'sedia ada' sebagai produk berkomersial di dalam industri penggalakan pelancongan negara. Susulan dari itu, tarikan pelancong untuk datang ke negara kita boleh diolah dan diinovasikan melalui integrasi tiga komponen iaitu universiti, agensi pelancongan dan komuniti setempat. Integrasi tersebut boleh mewujudkan kerjasama ke arah menengahkan unsurunsur sejarah tempatan dari pelbagai aspek seperti seni tampak, budaya dan corak persekitaran. Universiti menjadi peranan utama untuk direalisasikan sebagai destinasi pertama pelancong sebelum menuju ke mana-mana destinasi lain. Secara rasionalnya, UiTM Cawangan Perak boleh berperanan sebagai sebuah pusat transit akademik pelancongan bercorak informasi akademik berkomersial melalui kerjasama dengan agensi pelancongan dan komuniti setempat. Ini merupakan satu inovasi akademik yang boleh dilaksanakan melalui mekanisma universiti iaitu membawa universiti kepada masyarakat dan bukan masyarakat kepada universiti. Ini merupakan nilai tambah dalam memantapkan
\end{abstract}


penyampaian maklumat yang dikongsikan bersama untuk dimanfaatkan untuk kepentingan umum, seiring dengan objektif universiti untuk meningkatkan hubungan dan kerjasama dengan organisasi luar dalam kegiatan jaringan industri dalam membantu negara Malaysia melalui industri penggalakkan pelancongan. Usaha ini akan berjaya bila adanya penglibatan menyeluruh warga universiti (UiTM Perak) beserta agensi pelancongan, komuniti tempatan, kerajaan negeri dan agensi-agensi kerajaan atau swasta yang sedia memberi komitmen dan kerjasama yang terbaik.

Katakunci: integrasi, universiti, transit pelancong, komuniti

eISSN: 2550-214X (C) 2018. The Authors. Published for Idealogy Journal of Arts and Social Science by UiTM Press. This is an Open Access article distributed under the terms of the Creative Commons Attribution-NonCommercial-NoDerivatives License (http://creativecommons.org/licenses/by-nc-nd/4.0/), which permits non-commercial re-use, distribution, and reproduction in any medium, provided the original work is properly cited, and is not altered, transformed, or built upon in any way.

\section{PENDAHULUAN}

Pelancongan adalah satu produk yang unik yang merupakan satu campuran unsur ketara dan tidak ketara yang dialami oleh pelancong bahkan ianya juga merupakan gaya hidup dan diiktiraf sebagai komponen penjanaan ekonomi dikebanyakkan negara dan ini bersesuaian dengan kepelbagaian tarikan pelancong yang meliputi tinggalan sejarah, alam semulajadi sehinggalah kepada kebudayaan dan perilaku masyarakat setempat. Kesemua faktor ini sebenarnya boleh meningkatkan peratusan ketibaan pelancong asing ke sesebuah negeri di Malaysia yang mempunyai nilai-nilai keaslian dalam pelbagai aspek tarikan pelancong. Malaysia kini mempunyai potensi dalaman yang amat banyak yang bersifat unik dari segi fizikal dan kesemulajadian dari hasil ciptaan Allah SWT bagi menarik ramai pelancong dalam dan luar negara bagi menghayati kehebatan dan keunikan ciptaanNya. Malaysia satu-satunya negara pada masa ini amat terkenal dan dikenali pihak luar sebagai sebuah negara membangun dengan pesat melalui hasil usaha kerajaan dan rakyatnya yang saling bertungkus lumus membawa negara ini terkenal dengan perbagai budaya dan masyarakat yang bersifat majmuk membina kehidupan yang harmoni dan aman damai . Sektor pelancongan negara menunjukkan peningkatan untuk muncul sebagai penyumbang pendapatan negara kasar (PNK) ketiga tertinggi negara tahun lepas walaupun jumlah ketibaan pelancong menunjukkan kemerosotan.

Menurut Laporan Tahunan Program Transformasi Negara (NTP) $2015^{1}$, dari segi resit pelancongan, ia menurun sebanyak 4 peratus daripada RM72 bilion kepada RM69.1 bilion pada 2015, manakala jumlah ketibaan pelancong merosot sebanyak 6.3 peratus daripada 27.4 juta orang pada 2014 kepada 25.7 juta orang tahun lepas. Kemerosotan dalam ketibaan pelancong dan resit pelancongan itu boleh dikaitkan dengan kelembapan dan cabaran ekonomi global seperti banjir terburuk dalam tempoh 30 tahun lepas, yang menjejaskan beberapa negeri di Malaysia pada awal 2015, gempa bumi di Ranau, Sabah pada Jun 2015, nasihat perjalanan serantau bagi kawasan tenggara pantai Sabah selain kesan kemalangan pesawat MH370 dan MH17.

" Walaupun berlaku cabaran, sektor pelancongan kekal kukuh dan menjadi antara tonggak ekonomi yang dapat membantu pemulihan ekonomi," kata laporan itu. Laporan itu, yang dikeluarkan Unit Pengurusan Prestasi dan Pelaksanaan (Pemandu) di Jabatan Perdana Menteri, dilancarkan Perdana Menteri Datuk Seri Najib Tun Razak di Angkasapuri . Laporan itu menyatakan bahawa insentif dan program kerajaan terus memainkan peranan penting dalam pembangunan industri pelancongan, sebagai contoh, Elaun Cukai Pelaburan menggalakkan pembukaan lebih banyak hotel bertaraf 4 dan 5 bintang pada 2015 termasuk hotel mewah 5 bintang jenama Kempinski yang akan memulakan pembinaannya pada 2016. Dalam bergerak maju ke hadapan, kerajaan juga komited untuk mencapai sasaran 36 juta pelancong dan RM168 juta resit pelancong menjelang 2020, dengan 2015 menandakan separuh daripada Program Transformasi Ekonomi dan menjadi landskap dinamik bagi sektor pelancongan.

"Kementerian Pelancongan dan Kebudyaan telah membuat keputusan bahawa sudah tiba masanya untuk mengkaji semula inisiatif sedia ada dan mengenal pasti produk baharu yang ditawarkan termasuk menyelaras cadangan kajian yang dilaksana kementerian baru-baru ini," katanya. ( Sumber : Bernama , April 27, 2016 08:00 MYT ). ${ }^{2}$ YAB Datuk Seri Najib Tun Razak berkata, kerajaan akan 
melaksanakan langkah-langkah segera bagi menangani kesan krisis ekonomi global terhadap industri pelancongan di negara ini. Perdana Menteri memberi jaminan, setiap cadangan dan pandangan yang dikemukakan oleh pemain- pemain industri, pakar serta aktivis dalam industri pelancongan akan diberi perhatian sewajarnya oleh kerajaan melalui Kementerian Pelancongan dan Kebudayaan. Beliau berkata, kerajaan juga akan mengumumkan langkah-langkah memperkukuhkan industri pelancongan negara dari semasa ke semasa. "Yang pasti, industri ini bersifat dinamik dan kerajaan sedar bahawa pendekatan kita mesti sentiasa bersifat fleksibel agar sesuai dengan isu serta tuntutan semasa," jelasnya.

Konsep integrasi dicadangkan sebagai satu langkah universiti bagi memulakan universiti ini sebagai satu tapak destinasi pelancongan di negeri Perak sebelum pelawat atau pelancong-pelancong luar memulakan destinasi mereka. Ini sebagai satu inisiatif universiti dan agensi pelancongan negeri dalam usaha membantu usaha kerajaan memperkukuhkan industri pelancongan negara dari masa ke semasa.

\section{KONSEP INTEGRASI}

Kertas ini merupakan satu inisiatif dari buah fikiran dari kalangan rakyat Malaysia sendiri untuk memupuk satu jalinan komuniti melalui tiga komponen iaitu masyarakat tempatan dan luar, pihak universiti tempatan dan agensi kerajaan. Di sini, pihak universiti akan menjadi satu destinasi pertama pelancongan sebelum menuju ke mana-mana destinasi lain. Konsep pembentukan berintegrasi bersifat universiti berkomuniti dijustifikasikan seperti berikut:

Pihak universiti mempunyai kapasiti dalaman tersendiri, mempunyai pengalaman dalam industrial knowledge boleh menyediakan informasi berkaitan alam bina dan seni reka . Ini kerana universiti telah berjaya melahirkan graduan dalam pelbagai bidang yang berkaitan dengan alam bina dan seni reka. Oleh itu, universiti ini boleh berperanan bersama dalam membangunkan industri pelancongan negara terutamanya di negeri Perak.

Pihak universiti boleh dijadikan hub destinasi panduan atau rujukan dan sebagai satu transit pelancong sebelum ke mana-mana destinasi dalam negeri Perak.

Pihak universiti dan mana-mana agensi, boleh bekerjasama dengan pihak industri pelancongan negara/negeri melalui hubungan industri (industrial linkages). Usahasama seperti ini boleh meningkat daya maju industri dan pengembangan akademik universiti . Ini merupakan satu enovasi baru dalam penyampaian ilmiah yang boleh integrasikan bersama warga universiti dan pihak komuniti luar.

Sebagaimana sedia maklum, UiTM Perak amat berpotensi sekira mendapat sokongan padu dari mana-mana pihak luar untuk membantu dalam apa jua bentuk sama ada dari segi kemudahan fizikal, dana atau sebagainya; dengan yakin pihak universti dan pihak yang boleh bekerjasama untuk menjana pendapatan sebagai usaha membantu kerajaan untuk mengurangkan kos pasarana universiti-universiti di negara ini.

Kedudukan universiti yang strategik yang terletak di Perak Tengah atau berada di lingkaran tengah yang menghubungi bandar Ipoh, Seri Iskandar dan Lumut yang dianggap strategik memandu laluan pelancong ke arah barat Negeri Perak selain dari arah Lebuhraya Utara - Selatan dan Cameron Highland di sebelah timur. Ini merupakan satu kelebihan kerana kawasan yang berhampiran universiti masih wujud perkampongan tradisi yang mewarisi rumah-rumah tradisi lama (atau rumah KUTAI); Sungai Perak yang merupakan pensempadanan dalaman yang mempunyai sistem perhubungan yang terdapat kesan-kesan tinggalan sejarah, keadaan topografi yang mengandungai kawasan hutan hijau , kawasan ternakan tuntung dan kawasan peninggalan industri perlombongan. Sekiranya menghala ke Lumut, terdapat pula kawasan yang dijadikan sebagai zon industri dan zon pelancongan. Maka,dengan kedudukan universiti berada di lokasi strategik dan ini merupakan faktor utama menampilkan pelbagai aktiviti dan hasil karya pelajar dan juga pensyarah. 
Pada kedudukan yang sama, pelajar dan pensyarah boleh menampil sebarang hasil kerja mereka sama ada secara persembahan yang berkaitan penilaian akademik dan persembahan ini boleh diketengahkan atau atau dicadangkan sebagai persembahan yang boleh dikomersialkan.

Cadangan universti untuk bekerjasama dengan agensi pelancongan ialah untuk mempertingkatkan taraf sosio ekonomi negeri melalui hubungan komuniti universiti dengan pihak luar dan mewujudkan universiti ini sebagai satu hub pelancongan atau satu transit utama dan juga pusat rujukan ilmiah komuniti yang pertama di negeri Perak.

\section{CADANGAN PEMBENTUKAN INTEGRASI}

Merujuk konsep (1.1) dan (1.7), kertas kerja mengutamakan pembangunan integrasi dalaman yang boleh diusahasama dengan agensi pelancongan negeri; ini boleh dijelaskan bahawa peranan universiti bersama agensi pelancongan negeri dan komuniti luar boleh menjadi pemangkin utama dalam menggalakkan kedatangan pelancong ke Malaysia terutamanya di negeri Perak.

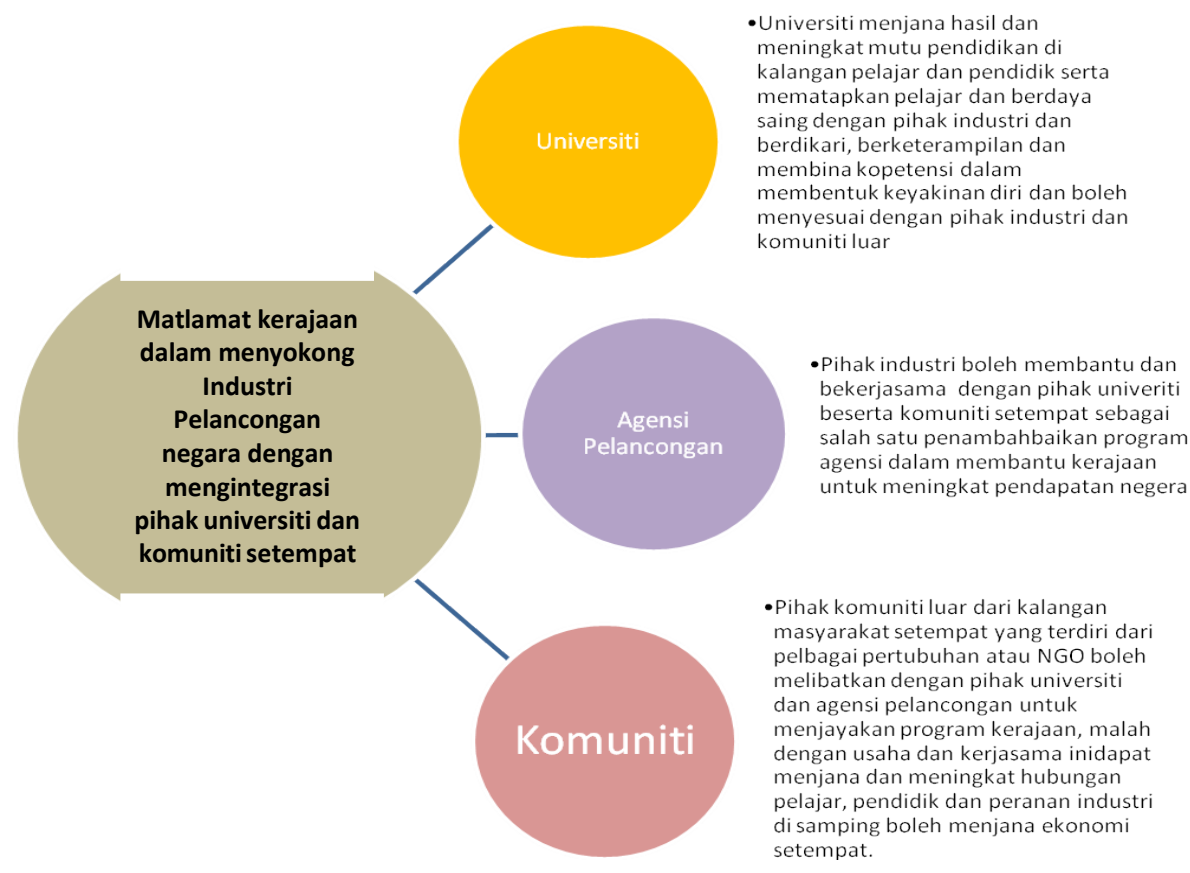

Rajah 1: Komponen Integrasi : Universiti, Agensi Pelancongan dan Komuniti 

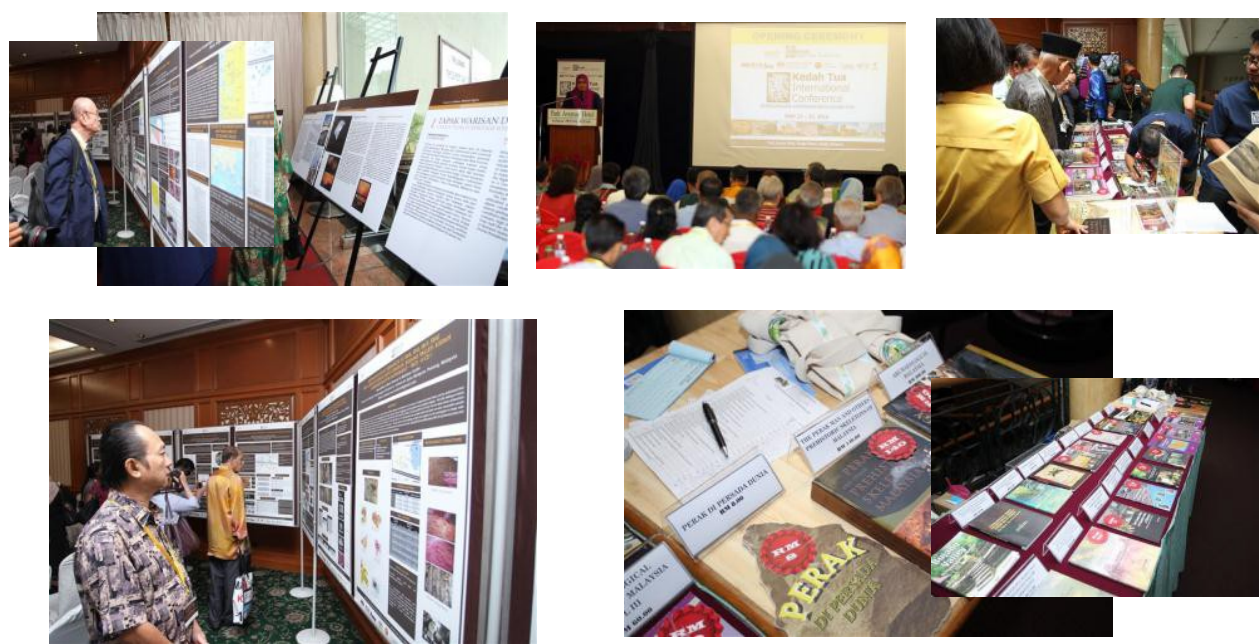

Gambar 1: Universiti sebagai transit/platfom Informasi pelancong

\subsection{Bagaimana Integrasi Ini Boleh Diwujudkan?}

Integrasi memberi keutamaan kepada universiti yang mempunyai kewibawaan tersendiri yang boleh menerajui dan berkemampuan untuk menjalinkan warga universiti dari peringkat atas sehingga di peringkat bawahan. Kesemua itu mempunyai nilai tersendiri dalam menjayakan integrasi untuk membawa universiti kepada masyarakat dan bukan masyarakat kepada universiti. Falsafah asal universiti tidak akan berubah tetapi falsafah yang sama boleh memberi impak kepada universiti untuk membudaya warga universiti itu sendiri melalui jalinan dua hala dalam bentuk pengkongsian ilmu, berinteraksi, dan bekerjasama untuk memasyarakatkan universiti supaya tidak ada jurang antara pihak komuniti dan sebagainya. Apatah lagi penglibatan industri atau agensi kerajaan yang boleh digabungkan bagi memantapkan kerjasama dan lebih mudah dan tidak ada perbezaan yang ketara; terutama dari aspek ilmu yang berbentuk teori dan praktikaliti yang seharusnya dibincangkan secara bersama supaya ilmu yang lebih jelas dan realiti itu dapat diterjemah kepada warga universiti terutamanya pada generasi pelajar kini yang serba jauh dari asal usul ilmu itu sendiri sama ada ilmu yang bersifat duniawi dan ukhrawi.

Di peringkat universiti melalui program sedia ada:

Universiti Teknologi Mara Perak boleh disebut sebagai "universiti komuniti” melalui objektif utamanya untuk meningkatkan hubungan dan kerjasama dengan organisasi luar dalam kegiatan jaringan industri, maka dengan ini amat sejajar dengan kehendak kertas kerja ini untuk mengmbil langkah secara berinovatif dalam konteks ilmu dan komuniti.

Selaras dengan pelbagai disiplin program universiti, sebagai contohnya, UiTM Perak sendiri mempunyai lima fakulti utama:

1. Fakulti Senibina Perancangnan dan Ukur (FSPU)

2. Fakulti Senilukis dan Seni Reka (FSSR)

3. Fakulti Sains Komputer dan Matematik ( beroperasi di Kampus Tapah )

4. Fakulti Pengurusan Perniagaan ( beroperasi Kampus Tapah )

5. Fakluti Perakaunan ( beroperasi Kampus Tapah )

Pihak Universiti menamakan dua fakulti iaitu FSPU dan FSSR bagi peringkatan permulaan kerana kedua-kedua fakulti tersebut terdapat program-program diploma dan ijazah yang boleh diintegrasi dan diperkukuhkan melalui jalinan industri . 
Fakulti Senibina Perancangan dan Ukur (FSPU) yang mempunyai lapan (8) jabatan utama iaitu: Jabatan Senibina, Jabatan Perancang Bandar dan Wilayah, Jabatan Ukur Bahan, Jabatan Pengurusan dan Penilaian Tanah, Jabatan Bangunan, Jabatan Senibina Dalaman, Jabatan Senibina Lanskap, Jabatan Ukur Bangunan; yang merangkumi program Diploma ( Perancang Bandar dan Wilayah, Ukur Bahan, Ukur Bangunan, Pengurusan Hartanah, Bangunan, Senibinan Dalaman, Lanskap), dan Ijazah ( Sarjana Muda (Sains ) Senibina, Ukur Bahan, Ukur Bangunan )

Fakulti Seni Lukis dan Seni Reka (FSSR) pula mempunyai disiplin program diploma dan ijazah tersendiri mengikut jabatan berikut: : Diploma in Art and Design ( Photography \& Digital Imaging), Diploma in Art and Design ( Fine Art, Fashion Design,Ceramic,Industrial Design, Fine Metal, Textile, Printing Technology, Graphic Design \& Digital Media ), Bachelor In Creative Photomedia (Honors), Bachelor In Fashion Design (Honors), Bachelor In Industrial Ceramics (Honors), Bachelor In Industrial Design (Honors), Bachelor In Comtemporary Metal Design (Honors), Bachelor in Textile Design (Honors), Bachelor In Graphic Design (Honors), Bachelor In Visual Culture (Honors), Bachelor (Hons) In Art \& Design (Printing Technology) dan Bachelor(Hons) In Fine Art

Integrasi akademik dalaman universiti terutamanya dari Fakulti Senibina Perancangan dan Ukur (FSPU) dan Fakulti Senilukis dan Seni Reka (FSSR) mempunyai potensi tersendiri dalam penyampaian ilmiah secara teori dan praktikal. Maklumat tersebut boleh dikaitkan dengan budaya setempat yang boleh dijalinkan bersama komuniti dan agensi pelancongan dalam memperkenalkan budaya dan kehidupan masyarakat di negeri Perak kepada pelancong atau pelawat luar dan dalam negeri.
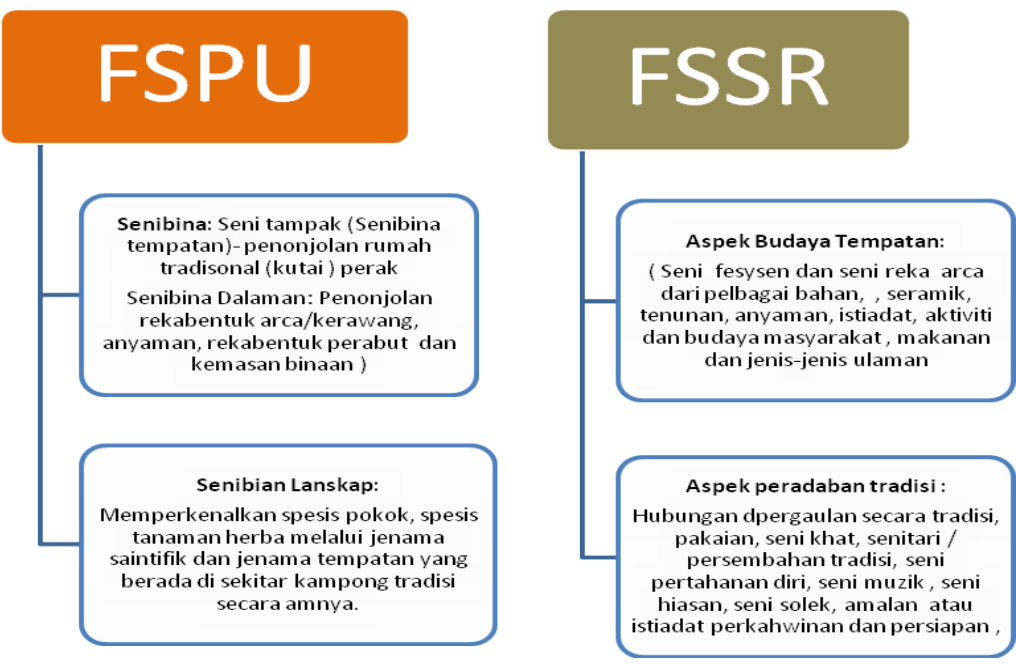

Rajah 2: Keupayaan dan peranan Universiti yang boleh diterjemah bersama komuniti dan agensi pelancongan

Sesuai dengan adanya 'KUTAI' (Institute for Knowledge \& Understanding of Tropical Architecture \& Interior.) di UiTM Perak. "Universiti merupakan satu-satunya universiti yang mempunyai fakulti yang terlibat dengan bidang reka bentuk dan alam bina di Negeri Perak Darul Ridzuan. Melalui penubuhan Institut KUTAI bidang ini akan diterokai dengan lebih mendalam melalui aktiviti-akviti penyelidikan dan akan menjadikan UiTM Perak sebagai pusat rujukan dunia dalam bidang alam bina tropika dan alam Melayu sekaligus meletakkan nama UiTM di peta dunia”. (Pautan: : http://perak.uitm.edu.my/kutai/index.php? emid=60\&lang=ms). Sehubungan itu pihak UiTM Perak berhasrat untuk menjadikan kampus ini sebagai pusat rujukan reka bentuk dan alam bina tropika di alam Melayu . Maka melalui KUTAI, universiti boleh menyumbang maklumat untuk rujukan pelancong dan ini menepati dengan gagasan universiti sebagai sebuah universiti bermaklumat dan boleh disampaikan untuk kepentingan semua pihak. 
Persediaan awal di peringkat universiti ialah mewujudkan sebuah replika bangunan asal ( sebagai contoh, membawa rumah kutai lama ke dalam laman universiti dan dilokasikan di tempat yang paling strategik untuk tarikan palancong apabila di bawa ke destinasi pertama iaitu universiti.

Pihak agensi berkaitan boleh memberi sokongan padu melalui penyediaan maklumat berkaitan dengan industri pelancongan yang berkaitan Negeri Perak.

\section{MANFAAT KEPADA PELAJAR DARI ASPEK AKADEMIK DAN KEUSAHAWANAN DAN KEPENTINGAN UNIVERSITI}
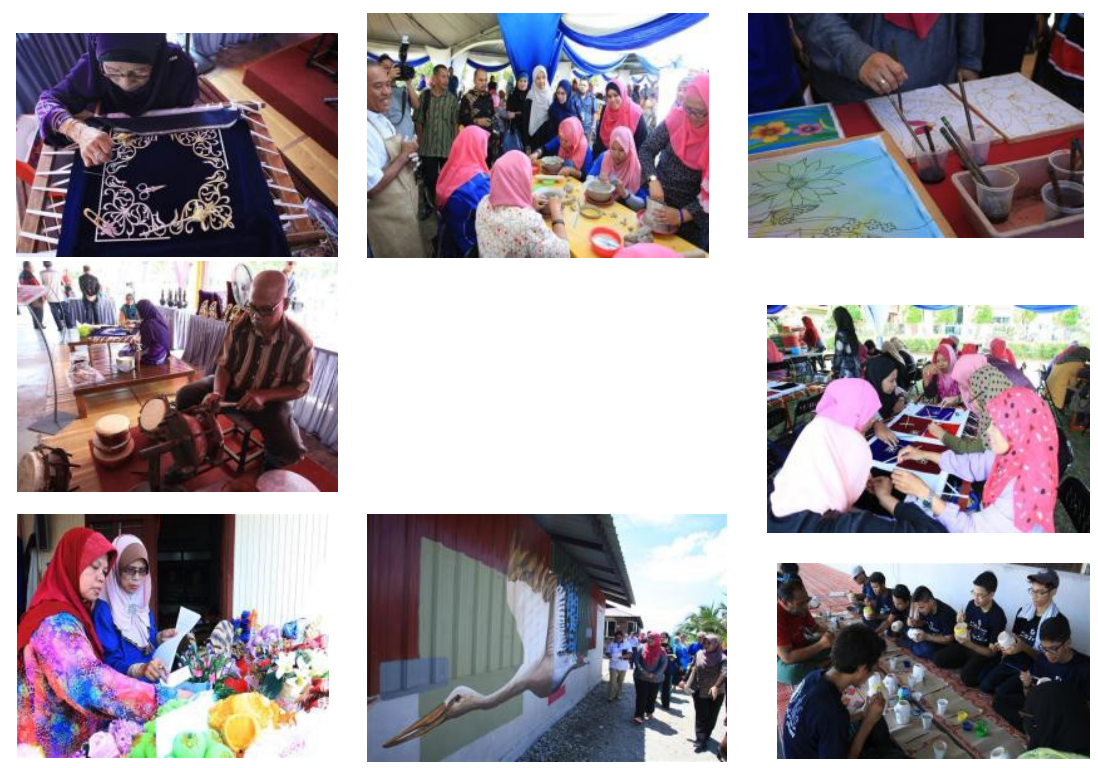

Gambar 2: Jalinan kepakaran Produk Universiti \& Komuniti

Penglibatan pelajar dan ahli akademik universiti melalui program masing-masing merupakan elemen utama dalam menjayakan maksud kertas kerja ini. Penglibatan pelajar amat diutamakan dan penting kerana ianya boleh dimanfaatkan melalui aspek berikut:

\section{Peringkat I:}

Pelajar melibatkan diri dalam komuniti / sosial , maka pelajar boleh dilatih untuk bekerjasama dan bertanggungjawab ( kehendak MOHE-LO5) dan memanfaatkan pengetahuan akademik melalui pembelajaran yang sedang dipelajari dan diintegerasikan bersama maklumat yang sedia ada secara kerjasama dengan agensi pelancongan.

\section{Peringkat II:}

Pelajar mendapat faedah dari aspek akademik kerana hasil kerja atau projek yang diketengahkan sebagai satu projek akademik. Ini boleh diprogramkan melalui kerjasama dengan pihak agensi pelancongan; maka ianya akan dinilai sebagai hasil kerja pelajar dan dikomersialkan; Pelajar juga dinilai dari aspek keupayaan berkomunikasi, nilai etika, berkepimpinan dan berprofesionalisme dalam menyedia, menyampai dan mengurus maklumat melalui pembelajaran dari universiti dan seterusnya sebagai hasil pembelajaran sepanjang hayat yang boleh diaplikasi selepas tamat pengajian ( kehendak MOHE-LO7). Hasil ini akan memberi manfaat kepada pelajar dan univesiti sebagai nilai tambah dan maklumat tersebut boleh dijadikan bahan rujukan oleh mana-mana pihak luar dan pihak berkepentingan. 


\section{Peringkat III:}

Penglibatan pelajar dan pihak akademik digalakkan kerana ini memberi manfaat kepada universiti dalam menjalinkan hubungan universiti dan industri. Melalui mekanisma ini, satu keberuntungan boleh membawa kebaikan kepada universiti dan agensi luar (agensi pelancongan) dalam mempelopori cara hidup dan budaya tempatan terutama di negeri Perak, melalui persediaan maklumat yang betul; dan universiti juga dijadikan bahan rujuk utama dalam hal-hal berkaitan dengan aktivitidan kajian yang berkaitan perlancongan.

\section{SUMBANGAN UNIVERSITI \& HASIL KEPADA UNIVERSITI, AGENSI DAN KOMUNITI}

Sumbangan Universiti (UiTM) - Ini melibatkan kerjasama Pelajar dan Pensyarah Program:

\begin{tabular}{|c|c|c|}
\hline Sul & ah & $\begin{array}{l}\text { Kebolehupayaan } \\
\text { entreprenuership } \\
\text { / industri }\end{array}$ \\
\hline $\begin{array}{r}\text { Kepim } \\
\text { Sebagai moderator } \\
\text { sudut penya } \\
\text { persem }\end{array}$ & $\begin{array}{r}\mathrm{K} \\
\text { berko } \\
\text { menca } \\
\text { akredita }\end{array}$ & Tercapai \\
\hline $\begin{array}{l}\text { Persembahan hasil kerja } \\
\text { akademik : } \\
\text { Hasil kerja pelajar yang berkait } \\
\text { dengan ciri-ciri budaya tempatan dan } \\
\text { kemahiran kerja tangan, kraftangan, } \\
\text { fotografi, rekabentuk arca, tembikar, } \\
\text { seni ukir, seni anyaman dll. }\end{array}$ & $\begin{array}{c}\text { Nilai dan hasil } \\
\text { Persembahan yang } \\
\text { berkualiti boleh dinilai } \\
\text { sebagai pemarkahan / } \\
\text { skor terbaik }\end{array}$ & $\begin{array}{l}\text { Hasil persembahan yang } \\
\text { berkualiti boleh dipaten dan } \\
\text { dikomersialkan. Penilaian luar } \\
\text { boleh dilibatkan dalam } \\
\text { peringkat ini }\end{array}$ \\
\hline $\begin{array}{l}\text { Peranan pelajar : } \\
\text { Sebagai penyampai maklumat } \\
\text { kepada pihak luar berkaitan nilai } \\
\text { seni dan konsep melalui hasil }\end{array}$ & $\begin{array}{l}\text { Nilai-lain 'soft skill' } \\
\text { boleh } \\
\text { diterapkan di peringkat } \\
\text { ini }\end{array}$ & $\begin{array}{l}\text { Penilaian luar dari pihak } \\
\text { industry mengikut program boleh } \\
\text { dilibatkan dalam peringkat ini }\end{array}$ \\
\hline $\begin{array}{l}\text { Persediaan Fizikal : } \\
\text { Mewujudkan sebuah galeri, } \\
\text { booth (jualan cenderahati), } \\
\text { pameran hasil kerja pelajar (secara } \\
\text { media atau peralatan/arca dll) }\end{array}$ & $\begin{array}{l}\text { Persediaan oleh universiti } \\
\text { dengan Kerjasama } \\
\text { akademik dan pelajar } \\
\text { boleh terlibat secara } \\
\text { menyeluruh }\end{array}$ & $\begin{array}{l}\text { Sumbagan kepakaran } \\
\text { dalaman dari ahli } \\
\text { akademik fakulti dan } \\
\text { jalinan industri }\end{array}$ \\
\hline
\end{tabular}

\subsection{Nilai tambah kepada Universiti}

Konsep Kertas kerja ini untuk memasyarakatkan universiti bersama industri dan komuniti setempat maka membentuk satu falsafah dalam memertabatkan universiti berdaya maju dan boleh bersaing di peringkat global dan melonjak peranan universiti seperti berikut:

1. Universiti membentuk satu inovasi baru sebagai satu mekanisma dalam memertabatkan penyampaian akademik yang ada hubungkait dengan pihak komuniti tempatan dan agensi pelancongan tempatan bagi sebarang program pelancongan khususnya dari dalam dan luar negeri Perak dan seterusnya meletakkan universiti ini sebagai sebuah pusat transit akademik pelancongan dan ditambah fungsi di peringkat dalaman universiti sejajar dengan matlamat universiti memenuhi keperluan masa kini. 
2. Universiti sebagai institusi bagi membina keyakinan diri pelajar untuk berhadapan dengan situasi yang lebih realiti melalui kerjasama antara universiti dengan agensi pelancongan, maka ciri-ciri kepimpinan dan tanggungjawab sosial boleh diterapkan melalui wujudnya universiti ini sebagai satu pusat transit akademik pelancongan.

3. Universiti mengutamakan pelajar iaitu melahirkan pelajar yang mahir dalam menyampai maklumat dari aspek budaya dan sejarah penduduk setempat, seterusnya meletakkan Negeri Perak sebagai satu destinasi akademik yang mempunyai nilai-nilai sejarah yang tersendiri lagi tersohor. Pelajar boleh menjadi perantara kepada komuniti setempat dalam menyampaikan maklumat.

4. Universiti ini boleh menyediakan satu program jangka pendek bagi keperluan masyarakat atau komuniti setempat dalam membina minda komuniti pada generasi kini. Ini supaya pihak komuniti boleh memahirkan diri dalam bidang atau pengkhususan tertentu seperti dalam bidang anyaman, seni lukis, seni ukir, seni reka fesyen dan sulaman, seni fotomedia, seni fotografi, rekabentuk seramik, seni arca dan lain-lain.

5. Universiti ini, terutamanya UiTM Perak boleh dijadikan satu pusat sumber maklumat untuk keperluan ilmiah kepada agensi-agensi atau institusi pendidikan luar seperti sekolah atau kolej pendidikan dan sebagainya.

6. Agensi Pelancongan (AP) - Pengiktirafan agensi dan usahasama dengan pihak universiti amatlah diharapkan kerana ini boleh meningkatkan tambah nilai untuk sebarang program agensi dan boleh diterima di perkenalkan ke peringkat global. Sumbangan dan kepakaran agensi seperti : Khidmat nasihat dan latihan kepada universiti secara berterusan supaya universiti berupaya dalam meneruskan agenda industri pelancongan negeri; Menyedia dana dan kepakaran dalam membuat penyelidikan ilmiah dalam industri pelancongan yang berteraskan integrasi akademik dan komuniti; Elemen penting dalam menjayakan intergrasi ini ialah menyediakan bahan / maklumat seperti katalog dan manual rujukan pelancongan, cenderahati , kenderaan membawa masuk-keluar pelancong, pemandu pelancong dan membuat sesi taklimat ; Program dan Kerjasama Agensi : Kesesuaian masa mengikut kalender Agensi Pelancangon jika melibatkan program Tahun Melawat Malaysia, Kempen Melawat Malaysia perlu diselaras bersama dengan program pelajar dan program universiti bagi kesesuaian kedatangan pelawat dan ini supaya tiada pertindihan dalam pelan pengajian pelajar. Ini boleh dilaksanakan sepanjang tahun dan boleh diintegrasikan bersama dengan program akademik universiti.

7. Manfaat daripada Komuniti - Pihak komuniti turut sama membantu dan menyalurkan maklumat yang berkaitan budaya dan kehidupan masyarakat Melayu dan sejarahnya. Pengumpulan maklumat dari masyarakat setempat, sebagai contoh, perkampongan Melayu Tradisional yang mempunyai seni tampak tersendiri dan nilai-nilai sejarah dan adat dan tradisi yang tidak boleh dipisah sehingga kini. Ini merupakan maklumat utama yang boleh didedahkan kepada generasi kini dan ianya boleh dijadikan sumber rujukan penyelidik dan diperkenalkan kepada pemerhatian pelawat atau pelancong dari dalam dan luar negara. Komuniti juga menyalurkan kepakaran tradisi yang boleh dimuatkan bersama dengan kepentingan silibus universiti berteraskan konsep integrasi akademik dan sebagai pemudah cara. 


\section{SOKONGAN \& KEPERLUAN FIZIKAL UNTUK MENJAYAKAN INTEGRASI UNIVERSITI, AGENSI PELANCONGAN DAN PIHAK KERAJAAN}

Cadangan dan sokongan kepada keperluan fizikal perlu dipohon dan memerlukan kelulusan dari semua pihak supaya dapat menjayakan hasrat universiti untuk melaksanan usahasama ke arah memajukan industri pelancongan melalui konsep integrasi universiti, agensi dan komuniti.

Oleh itu, peranan pihak Agensi Pelancongan Negeri dan pihak Kerajaan Negeri boleh membantu dan mewujudkan usahasama dari aspek menyediakan pasarana khas atau keperluan fizikal untuk membentuk sebuah pusat transit akademik pelancongan yang berjaya dan satu-satunya universiti yang mempunyai hubungan dengan agensi dan komuniti demi mencapai kepentingan bersama dan seterusnya membantu kerajaan dalam melonjak sumber ekonomi dalam sektor industri pelancongan.

\section{KESIMPULAN}

Kertas kerja ini secara rasionalnya, ingin melonjakkan universiti iaitu UiTM Perak sebagai sebuah pusat transit akademik pelancongan bercorak informasi akademik yang boleh diintegrasikan bersama agensi pelancongan dan komuniti setempat. Ini merupakan satu inovasi dalam mekanisma universiti sebagai nilai tambah dalam memantapkan penyampaian maklumat yang boleh dikongsikan bersama komuniti setempat dan pihak-pihak luar, disamping menjayakan dan berhasrat untuk memasyarakat universiti dengan komuniti luar bersama agensi pelancongan dan seterusnya mewujudkan usahasama dalam memajukan negara Malaysia melalui industri pelancongan yang merupakan salah satu pemangkin negara dalam menjana pendapatan negara ini. Usaha ini akan berjaya bila adanya penglibatan menyeluruh dari kalangan pelajar dan ahli akademik universiti (UiTM Perak) beserta agensi pelancongan, komuniti tempatan, kerajaan negeri dan agensi-agensi kerajaan atau swasta yang sedia memberi komitmen dan kerjasama yang terbaik.

\section{RUJUKAN}

BERNAMA bertarikh 27 April 2016

Hussaini Amran, Langkah segera bantu sektor pelancongan. Tangani kesan krisis ekonomi global 28 Ogos $2015 \quad 1: 37 \quad$ AM

http://www.utusan.com.my/berita/nasional/langkah-segera-bantu-sektor- pelancongan1.129357\#sthash.wdXvyD3m.dpuf )

Laporan Tahunan Program Transformasi Negara (NTP) 2015 